\title{
ATTITUDES OF HEALTH CARE PROFESSIONALS ON PARENTAL PRESENCE DURING INVASIVE PROCEDURES AND RESUSCITATION: A CROSS- SECTIONAL STUDY IN EASTERN NEPAL
}

\author{
Shyam Prasad Kafle ${ }^{1 *}$, Mukesh Bhatta ${ }^{1}$, Namu Koirala ${ }^{2}$, Anupam Koirala ${ }^{3}$
}

\begin{abstract}
Affiliation
1. Assistant Professor, Department of Pediatrics and Adolescent Medicine, BPKIHS, Dharan, Nepal

2. Assistant Professor, Department of Nursing, Purbanchal University School of Health Sciences, Gothgaon, Morang.

3. Medical Officer, Letang PHC, Nepal

\section{ARTICLE INFO}

Received : 25 July, 2021
Accepted : 14 August, 2021
Published : 04 November 2021

(c) Authors retain copyright and grant the journal right of first publication with the work simultaneously licensed under Creative Commons Attribution License CC - BY 4.0 that allows others to share the work with an acknowledgment of the work's authorship and initial publication in this journal.
\end{abstract}

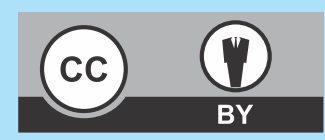

\section{ORA 268}

DOI: https://doi.org/10.3126/bjhs.v6i2.40357

\author{
* Corresponding Author \\ Dr. Shyam Prasad Kafle \\ Assistant Professor \\ Department of Pediatrics and Adolescent Medicine \\ BPKIHS, Dharan, Nepal \\ Email: kafle.shyam11@gmail.com \\ ORCID: https://orcid.org/0000-0001-6332-9880
}

\section{Citation}

Shyam Prasad Kafle, Mukesh Bhatta, Namu Koirala, Anupam Koirala. Attitudes of Health Care Professionals on Parental Presence During Invasive Procedures and Resuscitation: A Cross-sectional Study in Eastern Nepal. BJHS 2021;6(2)15. 1549-1555.

\section{ABSTRACT}

\section{Introduction}

Trends are changing to allow parents and families to be with their child during invasive procedures. Because of the intense workload, there is a tendency to overlook the parents' feelings. Attitudes of physicians and nurses are the common obstacles for this.

\section{Objective}

To determine health care professionals' attitudes toward parental presence during invasive procedures.

\section{Methodology}

A cross-sectional study was conducted among the health professionals in the department of Paediatrics and Adolescent Medicine of a tertiary care center in Eastern Nepal. Ethical clearance was obtained from the Institutional Review Committee of the institute. Total sample size was 112 (83 nursing staff and 29 physicians). Attitudes of physicians and nursing staff towards parental presence during various invasive procedures were recorded in the predesigned proforma. Data was entered in MS Excel and analysed using SPSS version 21.0. Frequency, percentage, mean, standard deviation, chi-square test, independent t-test and one-way ANNOVA were used for data analysis at $\mathrm{p}<0.05$.

\section{Result}

For the simple procedures like intravenous blood sampling and the simple wound repair or suture; majority of the health professionals (71.1\% to $79.3 \%$ ) agreed for parental presence. For other major procedures including resuscitations, majority (69.0\% to $85.5 \%$ ) disagreed for the parental presence. The most important factor considered was the child's request $(62.1 \%$ to $80.7 \%)$ for parental presence. The most likely reason for declining was unjustly blaming the medical staff for common/ simple complications (69.9\%). Only for the simple wound repair, statistically significant differences were noted between the physicians and the nursing staff $(p=0.033)$ on the basis of years of experiences where the physicians preferred for the parental presence.

\section{Conclusion}

Both the physicians and the nursing staff preferred not to allow the parents in the major invasive procedures including resuscitations whereas when the level of invasiveness decreased, the rate of approval increased in both the groups.

\section{KEY WORDS}

Attitude, Medical Staff, Parents 


\section{INTRODUCTION}

The family-centered model of health care has been increasingly gaining strength in recent decades, moving away from a paternalistic approach. ${ }^{1,2}$ Since the health and well-being of children can largely be attributed to their parents and caregivers, this change is especially important in paediatric practice procedures. Parents are now considered essential participants in the care of their children. It is now well-known fact that paediatric care should be provided within the context of the families. ${ }^{3-5}$ Studies have been conducted on parental presence during invasive procedures (IPs) in paediatric departments, such as blood collection for blood testing, lumbar punctures, suturing, and cardiopulmonary resuscitation (CPR)..$^{5-7}$ In 2000, the American Heart Association endorsed a guideline stating that parents should be given the option for their presence during their child's invasive procedure and/or resuscitation. ${ }^{3-8}$ Following this, the American Academy of Paediatrics (AAP), and the Society of Critical Care Medicine have followed the endorsement of parental presence during invasive procedures/ resuscitation. Most parents also believe that it is the right of both the parents and their child to be together during the invasive procedures. ${ }^{9-12}$

The relationship between health professionals and parents has again come into the light because of the increasing conflicts and assaults on the health personnel. The general public usually blame the health care professionals' attitude and behaviour as the main reason for the conflict. Many times, when there is the demise of the patient, the patient party blame for the negligence and lack of proper and timely care by the hospital team. This results in physical assaults to the hospital staff and damage to the hospital property also. Usually, a crowd on behalf of the demised person vandalizes the hospital property and equipment in anger. Parental presence during invasive procedures and patient management can change this scenario.

Health care professionals' (doctors and nurses) attitude toward parental presence during invasive procedures and patient management has changed in the last few decades. Recent studies have focused that most mothers prefer to stay with their children during painful and distressing invasive procedures. ${ }^{11}$ This helps to relieve the pain and distress of the child while providing a familiar environment with emotional support. ${ }^{2}$ Children also report that the presence of their parents is comforting during painful events. ${ }^{3}$ Randomized controlled studies in developed countries have confirmed that parental presence help in decreasing anxiety of both parents and children. ${ }^{4,5}$ However, health care professionals prefer to perform invasive procedures in the absence of parents. ${ }^{1,6}$

For improving the quality of service an agreement between the attitudes of physicians and nurses toward parental presence during invasive procedures is essential. This understanding is especially required in the dynamic environment of the paediatric department where there are limited resources and there is mostly overcrowding and the work burden is always massive. This decision should be made for parental presence immediately to avoid parental confusion, especially in the setting of the paediatric department though it may be against the parental presence. ${ }^{6}$ This requires hospital policy, guidelines and, a consensus between treating physicians and the nursing staff. Because of the intense workload, and fast patient turnover, there is a tendency to overlook the parents' feelings. However, parental presence helps in decreasing distress in children even if the procedure is simple and commonly performed. In addition, this allows the family to cope with the result, even if the child dies during

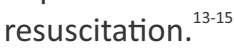

Many studies have found that most mothers preferred to participate during the invasive procedures. ${ }^{16,17} \mathrm{~A}$ recent randomized clinical trial also revealed that family members were systematically offered the choice of observing CPR which showed improved clinical indicators related to posttraumatic stress syndrome, better anxiety and depression scale scores, and less complicated grieving. ${ }^{14}$ Moreover, the attendee's presence during the resuscitation did not increase the level of stress on the health care providers.

The parental presence will help children cope effectively in case they are experiencing pain. Nearly all children stated that "having their parent" with them during the procedures will provide the most comfort when in pain. ${ }^{13}$ Yet, parents are often excluded from providing this support to their children. Especially, in more invasive procedures, health professionals often encourage parents to "wait outside" until the procedure is over believing that this will facilitate the child's cooperation. A variety of comforting and distracting strategies are used by parents to support their children during painful procedures. ${ }^{13,14}$

In Queensland, Australia a survey was conducted among 553 parents; where $93.9 \%$ of the parents expressed the desire to be present during the intravenous cannulation, $87.7 \%$ during nasogastric tube insertion, $83.4 \%$ during lumbar puncture, $83.9 \%$ during urinary catheter insertion, $77.8 \%$ during suprapubic bladder aspiration, 93.4\% during procedural sedation and $85 \%$ during a resuscitation where the possibility existed that their child might die. The most common reason reported by the parents was to provide comfort to their child (98\%). Similarly, the most common reason for not opting to present was the parental concern of disturbances during the procedures (33\%). Parental desire to be present decreased as the invasiveness of the procedure increasded. ${ }^{19}$

Trends are changing to allow parents and families to be with their child during invasive procedures, but the attitudes of physicians and nurses are the common obstacles for the family presence during resuscitation efforts. ${ }^{10}$ Health care professionals must overcome their anxiety, false beliefs, and fears to encourage families to meet their needs during lifesaving efforts on their children. ${ }^{20}$

From various studies, it is clear that parents want consultation regarding their presence during the invasive procedures. Parental presence may avoid or reduce confusion about the resuscitation process as their queries can be answered 
during the resuscitation efforts on their child. This study will bring out the attitude of health personnel on parental presence during invasive procedures in the paediatric setting. To the best of researchers' knowledge, there are no published studies on attitudes of health care professionals on parental presence during invasive procedures and resuscitation in Nepal. This study will fill this gap especially, in our settings.

Hence, the objective of this study was to determine health care professionals' (physicians and nurses) attitudes toward parental presence during invasive procedures.

\section{METHODOLOGY}

A descriptive cross-sectional, analytical study was conducted in the Department of Paediatrics and Adolescent Medicine of B. P. Koirala Institute of Health Sciences, Dharan, Nepal from February 2020 to March 2021. Census sampling method was applied and all the doctors including faculties, DM residents, senior residents, junior residents, and the medical officers participated voluntarily as physicians. Similarly, all the nursing staff working in the paediatric emergency, neonatal intensive care unit (NICU), paediatric intensive care unit (PICU), nursery, neonatal ward, and paediatric-wards I \& II participated voluntarily as nursing staff.

Health care professionals who refused to give consent or participate in the study or incomplete responses were excluded from the study. Of the total 125 health care professionals working in the department approached, 112 complete responses (83 nursing staff and 29 physicians) were received. Demographic characteristics of the participants such as; age, gender, current post at the hospital, duration of service, marital status, and parenthood were recorded in a predesigned proforma. Preferences about parental presence during each of the procedures with increasing invasiveness were asked in the order of intravenous blood sampling, simple wound repair/sutures, lumbar puncture, bone marrow aspiration/biopsy, central venous catheter insertion or burn debridement, resuscitation such as cardiopulmonary resuscitation, defibrillation, or intubation, and major resuscitation with risk of death. Attitudes of physicians and nursing staff towards parental presence during various invasive procedures along with the differences in the advantages and disadvantages regarding parental presence were recorded in the predesigned proforma.

Ethical clearance was obtained from the Institutional Review Committee of BPKIHS (IRC) (IRC No. 2039/ 020). Informed written consent was obtained from all the physicians and the nursing staff who participated in the study. The predesigned proforma along with the consent form was given to each of the participants. The contact number of the principal investigator (PI) was also mentioned in the proforma so that in case of doubt it can be resolved. All the participants were requested to fill the proforma independently. The identity of all the participants was kept confidential as there was only the provision of writing the post in the proforma. Data was entered in MS Excel and analysed using SPSS version 21.0. Frequency, percentage, mean, standard deviation, chi-square test, independent ttest and one-way ANNOVA were used for data analysis at $p<0.05$.

\section{RESULTS}

Out of 125 health care professionals approached, 112 complete responses were received. Other 13 responses were either incomplete or illegible and hence were discarded.

Table 1: Demographic Characteristics of the Health Care Professionals ( $\mathrm{N}=112$ )

\begin{tabular}{|l|l|l|l|l|}
\hline \multicolumn{2}{|l|}{ Characteristics } & \multicolumn{1}{|c|}{$\begin{array}{c}\text { Nurses } \\
(\mathrm{n}=83)\end{array}$} & $\begin{array}{c}\text { Physicians } \\
(\mathrm{n}=29)\end{array}$ & $\begin{array}{c}\text { P-value } \\
(\mathrm{p})\end{array}$ \\
\hline \multirow{2}{*}{ Age (years) Mean \pm SD } & $28.37 \pm 4.95$ & $31.48 \pm 3.39$ & $0.002^{*}$ \\
\hline \multirow{2}{*}{ Gender } & Male & $0(0 \%)$ & $17(58.6 \%)$ & \multirow{2}{*}{$<0.001^{\#}$} \\
\cline { 2 - 4 } & Female & $83(100 \%)$ & $12(41.4 \%)$ & \\
\hline \multirow{2}{*}{ Marital status } & Single & $41(49.4)$ & $12(41.4 \%)$ & 0.457 \\
\cline { 2 - 4 } & Married & $42(50.6)$ & $17(58.6 \%)$ & \\
\hline Parenthood & Yes & $28(33.7)$ & $7(24.1)$ & \multirow{2}{*}{0.337} \\
\cline { 2 - 4 } & No & $55(66.3)$ & $22(75.9)$ & \\
\hline $\begin{array}{l}\text { Years of experience } \\
\text { Mean } \pm S D\end{array}$ & $4.54 \pm 4.11$ & $2.62 \pm 2.3$ & $0.003^{*}$ \\
\hline
\end{tabular}

Values are given as $\mathrm{n}(\%)$ or mean \pm SD. "Pearson Chi-Square *independent t-test

The mean age of nursing staff working in the paediatrics department was $28.37 \pm 4.95$ years and that of physicians was $31.48 \pm 3.39$ years. All the nursing staff were female, and nearly half of them were married and one-third of them had at least a child. The mean years of experience for nursing staff was $4.54 \pm 4.11$ years whereas for physicians was $2.62 \pm 2.3$ years. There were statistically significant differences in the mean age $(p=0.002)$ and the years of experience $(p=0.003)$ between the physicians and the nursing staff (Table 1).

Table 2: Agreement ratings of the health care
professionals for parental presence during different
invasive procedures (N=112)
\begin{tabular}{|l|l|l|l|l|l|l|l|}
\hline \multicolumn{1}{|c|}{ Procedures } \\
\cline { 2 - 9 } \\
$\begin{array}{l}\text { must not } \\
\text { be present }\end{array}$ & $\begin{array}{l}\text { may be } \\
\text { present }\end{array}$ & $\begin{array}{l}\text { must be } \\
\text { present }\end{array}$ & $\begin{array}{c}\text { must not } \\
\text { be present }\end{array}$ & $\begin{array}{c}\text { may be } \\
\text { present }\end{array}$ & $\begin{array}{c}\text { must be } \\
\text { present }\end{array}$ & \#p-value \\
\hline $\begin{array}{l}\text { Intravenous blood } \\
\text { sample }\end{array}$ & $24(28.9)$ & $50(60.2)$ & $9(10.8)$ & $6(20.7)$ & $16(55.2)$ & $79(24.1)$ & 0.192 \\
\hline $\begin{array}{l}\text { Simple wound } \\
\text { repair/suture }\end{array}$ & $18(21.7)$ & $49(59.0)$ & $16(19.3)$ & $6(20.7)$ & $16(55.2)$ & $79(24.1)$ & 0.855 \\
\hline Lumbar puncture (LP) & $63(75.9)$ & $17(20.5)$ & $3(3.6)$ & $20(69.0)$ & $9(31.0)$ & $0(0.0)$ & 0.330 \\
\hline $\begin{array}{l}\text { Bone marrow } \\
\text { aspiration/biopsy }\end{array}$ & $71(85.5)$ & $10(12.0)$ & $2(2.4)$ & $23(79.3)$ & $5(17.2)$ & $1(3.4)$ & 0.734 \\
\hline $\begin{array}{l}\text { Central venous } \\
\text { catheterisation }\end{array}$ & $67(80.7)$ & $16(19.3)$ & $0(0.0)$ & $24(82.8)$ & $4(13.8)$ & $1(3.4)$ & 0.198 \\
\hline $\begin{array}{l}\text { Major resuscitation } \\
\text { (CPR, defibrillation, } \\
\text { intubations) }\end{array}$ & $70(84.3)$ & $10(12.0)$ & $3(3.6)$ & $23(79.3)$ & $3(10.3)$ & $3(10.3)$ & 0.380 \\
\hline $\begin{array}{l}\text { Major resuscitation } \\
\text { with risk of death }\end{array}$ & $66(79.5)$ & $14(16.9)$ & $3(3.6)$ & $22(75.9)$ & $4(13.8)$ & $3(10.3)$ & 0.372 \\
\hline
\end{tabular}

Values are given as $n(\%)$; \#Pearson Chi-Square

Regarding the parental presence for intravenous blood sampling; $71.0 \%$ of the nursing staff agreed whereas $79.3 \%$ of the physicians have agreed for the same. Similar is the agreement for the simple wound repair or suture where $78.3 \%$ of the nursing staff and $79.3 \%$ of physicians agreed for the parental presence during the procedure. For other 
procedures like LP, bone marrow aspiration or biopsy, central venous catheterization, other major resuscitations like (CPR, defibrillation, intubations) including major resuscitation with risk of death was not approved by $69.0 \%$, $79.3 \%, 82.8 \%, 79.3 \%, 75.9 \%$ of the physicians and $75.9 \%$, $85.5 \%, 80.7 \%, 84.3 \%$, and $79.5 \%$ of the nurses, respectively. This table showed that there was major disagreement on the parental presence by both the physicians and the nursing staff as the invasiveness of the procedure increased (Table 2 ).

Table 3: Factors that affect the health care professionals'
decision regarding the parental presence during the
procedures (N=112)

Values are given as n (\%);\#Pearson Chi-Square test * : Significant

Table 3 shows the different factors that were considered by the health personnel while allowing the parents to stay with their child during the invasive procedure. The two most common factors considered were the child's request and the level of invasiveness of the procedure while agreeing for the parental presence by the physicians (62.1\% and 62.1\%) and the nursing staff $(80.7 \%$ and $51.8 \%)$. The significant differences were noted in the efficiency of analgesia and sedation $(p=0.001)$, demographic and educational level of the parents $(p=0.017)$ and, the parental request to attend the child ( $p=0.002$ ) between the two groups.

\begin{tabular}{|c|c|c|c|c|}
\hline $\begin{array}{l}\text { Advantages reported by } \\
\text { healthcare professionals }\end{array}$ & & $\begin{array}{l}\text { Nurses } \\
\text { (83) }\end{array}$ & $\begin{array}{l}\text { Doctors } \\
\text { (29) }\end{array}$ & $\begin{array}{l}\text { \#P value } \\
\text { (p) }\end{array}$ \\
\hline \multirow[t]{2}{*}{ To comfort the child } & Yes & $14(16.9)$ & $7(24.1)$ & \multirow[t]{2}{*}{0.338} \\
\hline & no & $69(83.1)$ & $22(75.9)$ & \\
\hline \multirow{2}{*}{$\begin{array}{l}\text { Decrease the anxiety of the } \\
\text { child }\end{array}$} & Yes & $35(42.2)$ & $8(27.6)$ & \multirow[t]{2}{*}{0.165} \\
\hline & no & 48 (57.8) & $21(72.40)$ & \\
\hline \multirow{2}{*}{ Calm down the child } & Yes & $44(53.0)$ & $18(62.1)$ & \multirow[t]{2}{*}{0.398} \\
\hline & no & $39(47.0)$ & $11(37.90$ & \\
\hline \multirow{2}{*}{$\begin{array}{l}\text { Emotional and psychological } \\
\text { support to the child }\end{array}$} & Yes & $38(45.8)$ & $10(34.5)$ & \multirow[t]{2}{*}{0.290} \\
\hline & no & $45(54.2)$ & $19(65.5)$ & \\
\hline \multirow[t]{2}{*}{ Control and restrain the child } & Yes & $33(39.8)$ & $9(31.0)$ & \multirow[t]{2}{*}{0.403} \\
\hline & no & $50(60.2)$ & $20(69.0)$ & \\
\hline
\end{tabular}

Values are given as n (\%); \#Pearson Chi-Square *: Significant
The majority of the nursing staff (53.0\%) and the physicians $(62.1 \%)$ reported the main advantage of parental presence would be to calm down the child. The other advantages reported were emotional and psychological support to the child, a help to control the child during the procedure and, to decrease the anxiety of the child, in the decreasing order. The majority of the nursing staff $(83.1 \%)$ and the physicians (75.9\%) reported that it would be of no help to comfort the child (Table 4).

Table 5: Perceived disadvantages of parental presence during invasive procedures and resuscitation by health care professionals ( $\mathrm{N}=112$ )

\begin{tabular}{|c|c|c|c|c|}
\hline $\begin{array}{l}\text { Reasons Reported by } \\
\text { Healthcare } \\
\text { Professionals }\end{array}$ & & Nurses & Doctors & $\begin{array}{c}\text { \#P-value } \\
\text { (p) }\end{array}$ \\
\hline \multirow{2}{*}{$\begin{array}{l}\text { May unjustly blame } \\
\text { the medical staff for } \\
\text { common/ simple } \\
\text { complications }\end{array}$} & Yes & $58(69.9)$ & $13(44.8)$ & \multirow[t]{2}{*}{$0.016^{*}$} \\
\hline & No & $25(30.1)$ & $16(55.2)$ & \\
\hline \multirow{2}{*}{$\begin{array}{l}\text { May adversely affect } \\
\text { performance }\end{array}$} & Yes & $22(26.5)$ & $6(20.7)$ & \multirow[t]{2}{*}{0.533} \\
\hline & No & $61(73.5)$ & $23(79.3)$ & \\
\hline \multirow{2}{*}{$\begin{array}{l}\text { May arise } \\
\text { misunderstandings } \\
\text { and conflicts }\end{array}$} & Yes & $18(21.7)$ & $6(20.7)$ & \multirow[t]{2}{*}{0.910} \\
\hline & No & $65(78.3)$ & $23(79.3)$ & \\
\hline \multirow[t]{2}{*}{ They may panic } & Yes & 14 (16.9) & $8(27.6)$ & \multirow[t]{2}{*}{0.211} \\
\hline & No & 69 (83.1) & $21(72.4)$ & \\
\hline \multirow{2}{*}{$\begin{array}{l}\text { They may interrupt } \\
\text { during the } \\
\text { procedures }\end{array}$} & Yes & $52(62.7)$ & $25(86.2)$ & \multirow[t]{2}{*}{$0.018^{*}$} \\
\hline & No & $31(37.3)$ & $4(13.8)$ & \\
\hline
\end{tabular}

\section{\#PearsonChi-Square}

*: significant

The majority of the nursing staff reported that parental presence may result in unjustly blaming of the medical staff for common/ simple complications (69.9\%) whereas, only $44.8 \%$ of physicians reported the same and the difference was statistically significant $(p=0.016)$. The majority of the nursing staff reported that parental presence may cause interruption during the procedures (62.7\%) whereas, $86.2 \%$ of the physicians reported the same and this finding was statistically significant between the two groups ( $p=0.018)$ (Table 5).

Table 6: Mean years of experience of health care professionals who disapproved parental Presence for each of the procedures ( $\mathrm{N}=112$ )

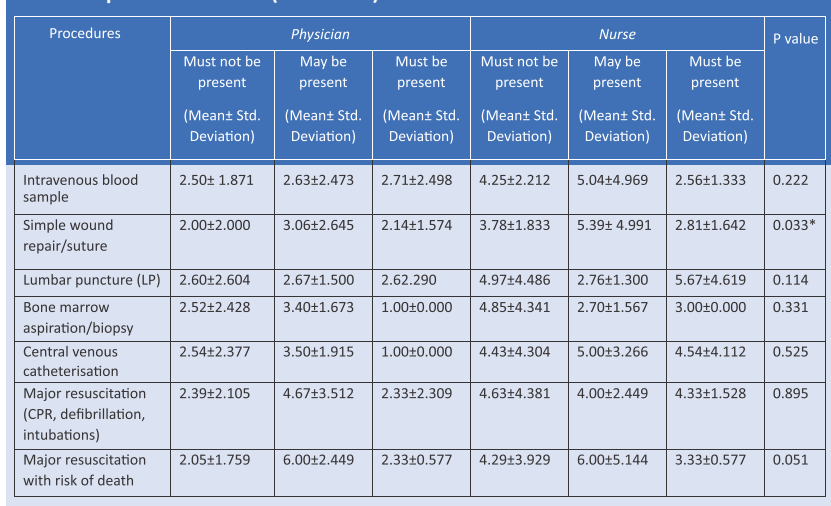

Values are given as mean years of experience $\pm S D$, ANNOVA test
$*$ : Significant 
Table 6 compares the mean years of experience between the nursing staff and the physicians for the disapproval of the parental presence. Out of the 6 procedures viz intravenous blood sampling, simple wound repair/suture, lumbar puncture (LP), bone marrow aspiration/biopsy, central venous catheterization, major resuscitation such as CPR, defibrillation, intubations and, major resuscitation with risk of death in the order of increasing level of invasiveness, only in the simple wound repair there were statistically significant differences between the physicians and the nursing staff $(p=0.033)$ based on years of experiences, where the physicians preferred for parental presence.

\section{DISCUSSION}

Quality of health care can be improved by the mutual understandings among health professionals, the patient, and their parents. Except for minor procedures, most of the time parents are not allowed to stay along with their children during the invasive procedures at our institute. Also, our institute does not have guidelines or policies to help or facilitate parental presence during complex invasive procedures and/or resuscitations. Many studies from different countries have shown that parents prefer to stay with their children and this has been advocated by the AAP since $2000 .^{3,20,21}$ Many parents believe that parental presence during the invasive procedures will help their child in decreasing pain and anxiety. There will be less sorrow and pain even if there is the demise of their child. ${ }^{11,15,22}$

Nursing staff accounted for 74.11 percent of the total respondents in our study, while physicians made up the remaining 25.89 percent. Physicians and nursing staff had statistically significant differences in mean age $(p=0.002)$ and years of experience (0.003), with nursing staff having $4.54 \pm 4.11$ years of experience and physicians having $2.62 \pm 2.3$ years. Because the bulk of the physicians who participated in the study were junior residents, the average years of experience for physicians was lower. In the study done in Turkey, similar results were noted. ${ }^{18}$ For the minor procedures such as intravenous sampling and the simple wound repair or suture, the majority of the nursing staff (71.1 and 78.3\%) and the physicians (79. 3 and 79.3\%) agreed on parental presence. There were no significant differences in the opinion regarding parental presence in the remaining invasive procedures between physicians and nurses, where the majority had declined for parental presence. Similar findings were also noted in Spain. ${ }^{25}$ In another study, 79\% of clinicians have reported that if their institution develops a policy and a guideline to support parental presence; they would allow parents during complex invasive procedures and resuscitations. ${ }^{24}$

The two key factors considered were child's request and the degree of invasiveness in which physicians $(62.1 \% 1$ and $62.1 \%)$ and nursing personnel $(80.7 \%$ and $51.8 \%)$ were in agreement for the presence of parents. However, significant differences were noted between physicians and nursing staff for considering the parental presence on 3 factors namely, the efficiency of analgesia and sedation $(p=0.001)$, in the demography and education of parents $(p=0.017)$, and parental request $(p=0.002)$ where physicians were in favour for the parental presence.

The major advantages reported by most of the healthcare professionals on parental presence were to calm down the child ( $53.0 \%$ by nursing staff and $62.1 \%$ by physicians) whereas, $45.8 \%$ of the nursing staff and $34.5 \%$ of the physicians reported that this will help in emotional and psychological support of the child. Nearly one-third of the respondents also reported that parental presence will also help in restraining the child and decreasing the anxiety of the child.

The two most common disadvantages perceived were the possibility of unjustly blame to the medical staff for common/ simple complications and interruption during the procedure, reported by nursing staff (69.9\%and $62.7 \%$ ) and by the physicians $(44.8 \%$ and $86.2 \%$ ) for which significant differences were noted between the two groups. Many studies have concluded that parents typically do not interfere with the medical care rendered to their children but rather observe quietly from a distance and/or emotionally support their child through verbal assurance or physical contact. ${ }^{26,27}$

Approval of the parental presence during invasive procedures decreased as the invasiveness of the procedure increased in both the physician and the nursing group. There was a significant difference in the simple wound repair or suture procedure where the nursing staffs were more reluctant to allow parental presence.

In our study, only in the simple wound repair, there were statistically significant differences between the physicians and the nursing staff $(p=0.033)$ based on the years of experiences where both the physicians and the nursing staff agreed for the parental presence. Similarly, Sacchetti et al had detected a significant correlation between personal experience of the health care professionals and agreement of parental presence during resuscitation of children. ${ }^{27}$ Meanwhile, various other factors are expected for agreeing on the parental presence such as cultural variances regarding pain threshold, concept of motherhood, view of anxiety, and coping strategies for stress etc.

\section{CONCLUSION}

Both the physicians and the nursing staff preferred not to allow the parents in the major invasive procedures including resuscitations whereas when the level of invasiveness decreased, the rate of approval increased in both the groups. Both the groups readily approved parental presence for the two minor procedures like intravenous blood sampling and the simple wound repair and or suture. But for the simple wound repair, there was statistically significant differences between the physicians and the nursing staffs $(p=0.033)$ on the basis of years of experiences where the physicians preferred for parental presence. 


\section{RECOMMENDATIONS}

In order to further encourage the presence of parents at even more invasive procedures, more work needs to be done by establishing working groups and formulating the hospital policy, guidelines and, a consensus between treating physicians and the nursing staff according to the socio cultural background.

\section{LIMITATIONS OF THE STUDY}

Our study is limited by our small sample size, and thus some results may not be representative of the health care professionals dedicated to the care of paediatric population of Nepal. In addition to the limitations inherent in any study that uses questionnaires, some differences may not be significant in our findings. Furthermore, faculties constituted nearly one-third of the physicians which might cause some bias.

\section{ACKNOWLEDGEMENT}

We would like to acknowledge the HOD, Department of Paediatrics and Adolescent Medicine, and Chief, Division of Neonatology, BPKIHS, Dharan for their support and guidance in conducting this study. We would also like to thank all the study participants for participating in this study, without whom this study would have been impossible. We would like to thank School of Public Health and Community Medicine for their assistance during data analysis.

\section{CONFLICT OF INTEREST}

There is no conflict of interest during the study.

\section{FINANCIAL DISCLOSURE}

None

\section{REFERENCES}

1. GamellFulla A, GamellFullà A, Corniero Alonso P, Parra Cotanda C, TrenchsSainz de la Maza V, LuacesCubells C. ¿Estánpresentes los padres durante los procedimientosinvasivos? Estudio en 32 hospitales de Espana. ₹AnPediatr (Barc). 2010;72:243-9., https:// doi.org/10.1016/j.anpedi.2009.11.014

2. Parra Cotanda C, LuacesCubells C, PouFernández J. ¿Deberíanestar presentes los padres durante los procedimientosinvasivos en urgencias? AnPediatr (Barc). 2009;70:293---6.https://doi.org/ 10.1016/j.anpedi.2008.09.005

3. American Heart Association; American Academy of Pediatrics. 2005 American Heart Association (AHA) guidelines for cardiopulmonary resuscitation (CPR) and emergency cardiovascular care (ECC) of pediatric and neonatal patients: neonatal resuscitation guidelines. Pediatrics. 2006;117(5). Available at: www. pediatrics.org/cgi/ content/ full/117/5/e1029 https://doi.org/10.1542/peds.2006-0349

4. Hazinsky MF, Zaritsky AL, Nadkarani VM, Hirkey RW, Schexnayder SM, Berg RA, eds. Coping with death and dying. In: PALS Provider Manual. Dallas, TX: American Heart Association, American Academy of Pediatrics; 2002:401-402

5. Maclean SL, Guzzetta CE, White C, et al. Family presence during cardiopulmonary resuscitation and invasive procedures: practices of critical care and emergency nurses. J EmergNurs. 2003;29:208 -221 https://doi.org/10.1067/men.2003.100

6. Moyer M. Pediatric advanced life support guidelines updated, part 2. Air Med J. 2002;21(4):17-19 https://doi.org/10.1016/S1067991X(02)70050-3

7. Moyer M. Pediatric advanced life support guidelines updated, part 1. Air Med J. 2002;21(4):26 -27 https://doi.org/10.1016/S1067991X(02)70034-5

8. O'Malley P, Brown K, Mace SE; American Academy of Pediatrics, Committee on Pediatric Emergency Medicine; American College of Emergency Physicians, Pediatric Emergency Medicine Committee. Patient-and family-centered care and the role of the emergency physician providing care to a child in the emergency department. Pediatrics. 2006;118:2242-224 https://doi.org/10.1542/peds.2006-2588

9. Basol R, Ohman K, Simones J, Skillings K. Using research to determine support for a policy on family presence during resuscitation. DimensCrit Care Nurs. 2009;28:237-47. https:// doi.org/ 10.1097/ DCC.0b013e3181ac4bf4

10. Pérez Alonso V, Gómez Sáez F, González-Granado LI, RojoConejo P. Procedimientosinvasivos en urgencias: ¿̇los familiares prefierenestar presentes? AnPediatr (Barc). 2009;70: $230-4$. https://doi.org/10.1016/j.anpedi.2008.10.017

11. Bauchner $\mathrm{H}$, Waring $\mathrm{C}$, Vinci R. Parental presence during procedures in an emergency room: results from 50 observations. Pediatrics. 1991 Apr;87(4):544-8. PMID: 2011433.

12. Boie ET, Moore GP, Brummett C, Nelson DR. Do parents want to be present during invasive procedures performed on their children in the emergency department? A survey of 400 parents. Ann Emerg Med. 1999;34(1):70-4.https://doi.org/10.1016/S0196-0644(99)70274-X

13. Broome, Marion. Helping parents support their child in pain. Pediatric nursing. 2000;26. 315-7.

14. De Stefano C, Normand D, Jabre P, et al. Family Presence during Resuscitation: A Qualitative Analysis from a National Multicenter Randomized Clinical Trial. PLoS One. 2016;11(6):e0156100. Published 2016 Jun 2. doi:10.1371/journal.pone. 0156100

15. Beckman AW, Sloan BK, Moore GP, Cordell WH, Brizendine EJ, Boie ET, et al. Should Parents Be Present during Emergency Department Procedures on Children, and Who Should Make That Decision? A Survey of Emergency Physician and Nurse Attitudes. AcadEmerg Med. 2002 Feb;9(2):154-8. https://doi.org/10.1111/j.15532712.2002.tb00234.x

16. Egemen A, Ikizoǧlu T, Karapinar B, Coşar H, Karapinar D. Parental presence during invasive procedures and resuscitation: Attitudes of health care professionals in Turkey. PediatrEmerg Care. 2006 Apr;22(4):230-4. https://doi.org/10.1097/01.pec. 0000210178. 86504.80

17. Nibert $L$, Ondrejka D. Family presence during pediatric resuscitation: An integrative review for evidence-based practice. J PediatrNurs [Internet]. 2005 Mar 4 [cited 2020 Jun 5];20(2):145-7. Available from: https://linkinghub.elsevier.com/retrieve/pii/ S0882596 304000946. https://doi.org/10.1016/j.pedn.2004.05.017

18. Karapinar B, Yilmaz D, Egemen A. Mothers' attitudes towards their own presence during invasive procedures on their children. Turk J Pediatr. 2005 Jan-Mar;47(1):46-52. PMID: 15884629.

19. Isoardi J, Slabbert N, Treston G. Witnessing invasive paediatric procedures, including resuscitation, in the emergency department: $A$ parental perspective. Vol. 17, EMA - Emergency Medicine Australasia. Blackwell Publishing; 2005. p. 244-8. https://doi.org/ 10.1111/j.1742-6723.2005.00730.x

20. Nibert L, Ondrejka D. Family presence during pediatric resuscitation: An integrative review for evidence-based practice. J PediatrNurs. 2005 Mar 4;20(2):145-7. https://doi.org/10.1016/j.pedn. 2004.05.017

21. Mangurten JA, Scott SH, Guzzetta CE, et al. Family presence: making room. Am J Nurs. 2005;105(5):40 - 48; quiz 49. https://doi.org/ 10.1097/00000446-200505000-00027 
22. McAlvin SS, Carew-Lyons A. Family presence during resuscitation and invasive procedures in pediatric critical care: a systematic review. Am J Crit Care. 2014 Nov;23(6):477-84; quiz 485. doi: 10.4037/ajcc2014922. PMID: 25362671. https://doi.org/ $10.4037 /$ ajcc2014922

23. Sacchetti A, Carraccio C, Leva E, et al. Acceptance of family member presence during pediatric resuscitations in emergency department: effects of personal experience. PediatrEmerg Care. 2000; 16:85-87. https://doi.org/10.1097/00006565-200004000-00004

24. Fein JA, Ganesh J, Alpern ER. Medical staff attitudes toward family presence during pediatric procedures. PediatrEmerg Care. 2004; 20:224-227.https://doi.org/10.1097/01. pec.0000121241.99242.3b
25 Angel Solà J, Sagué Bravo S, Parra Cotanda C, TrenchsSainz de la Maza V, LuacesCubells C. ¿Ha aumentado la presencia de los padres durante los procedimientosinvasivos en urgencias en los últimosaños? [Has the presence of parents during invasive procedures in the emergency department increased in the last few years?]. AnPediatr (Barc). 2015 Jan;82(1):6-11. Spanish. doi: 10.1016/j.anpedi.2014.02.004. Epub 2014 Mar 12. PMID: 24629904. https://doi.org/10.1016/j.anpedi.2014.02.004

26 Mangurten JA, Scott SH, Guzzetta CE, et al. Family presence: making room. Am J Nurs. 2005;105(5):40 - 48; quiz 49. https://doi.org/ 10.1097/00000446-200505000-00027

27 Sacchetti A, Paston C, Carraccio C. Family members do not disrupt care when present during invasive procedures. AcadEmerg Med. 2005;12:477-479. https://doi.org/10.1197/j.aem.2004.12.010 